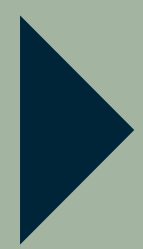




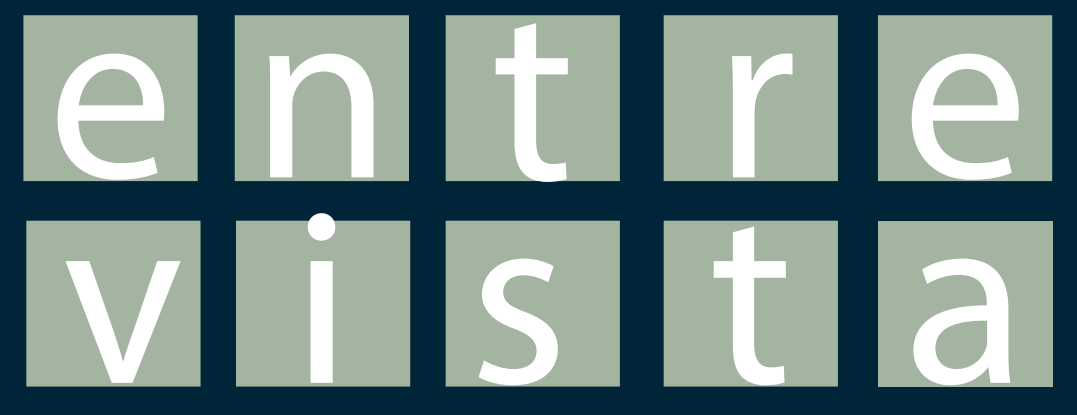




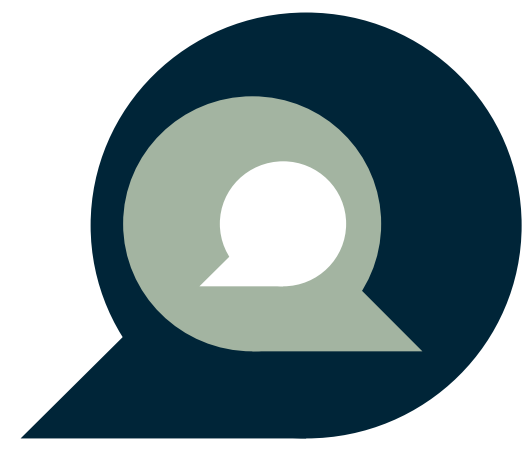




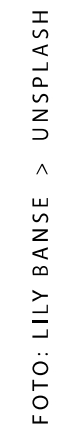

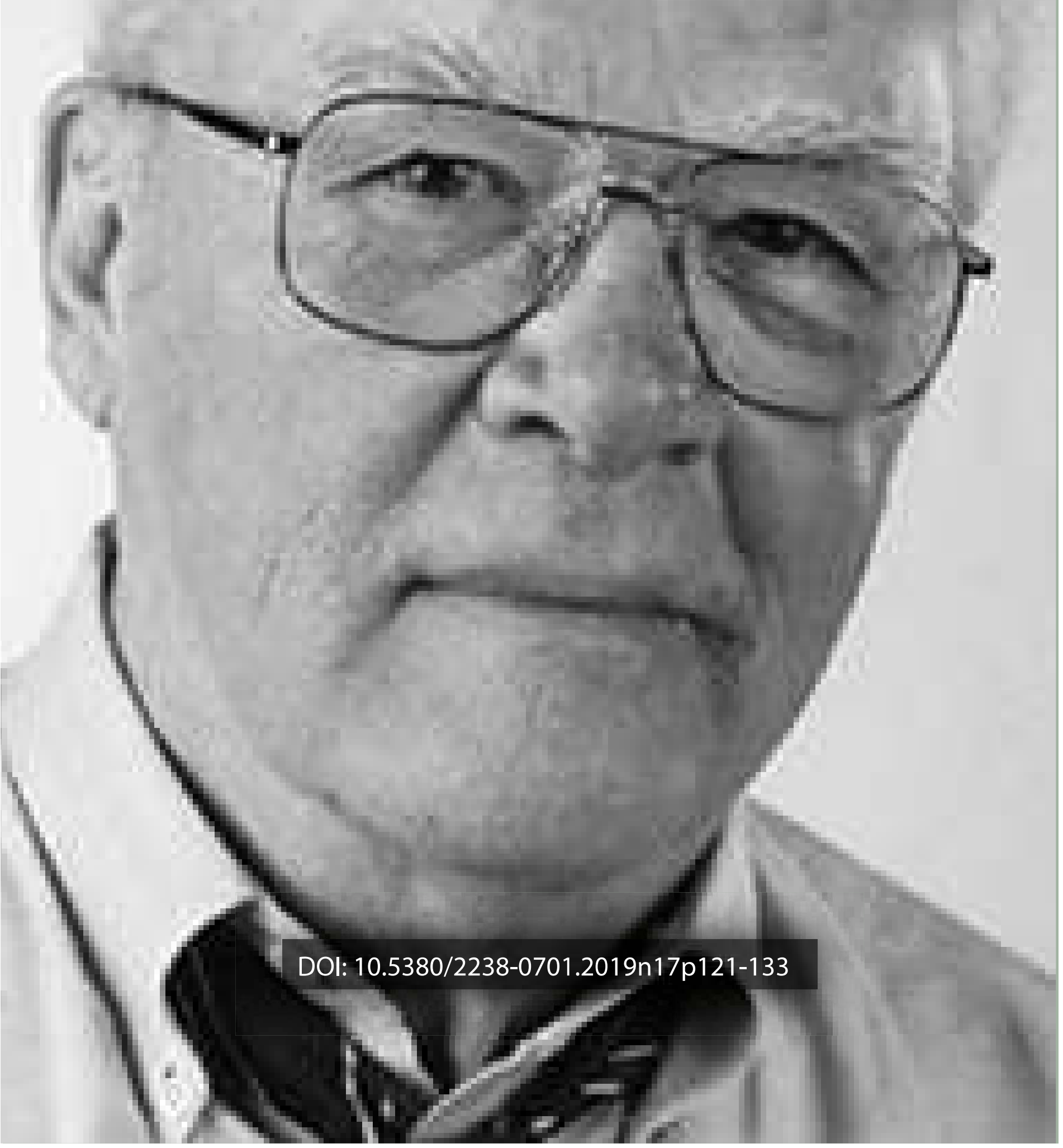


O Civic Journalism / Public Journalism examinado por um de seus criadores

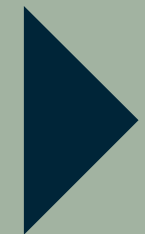




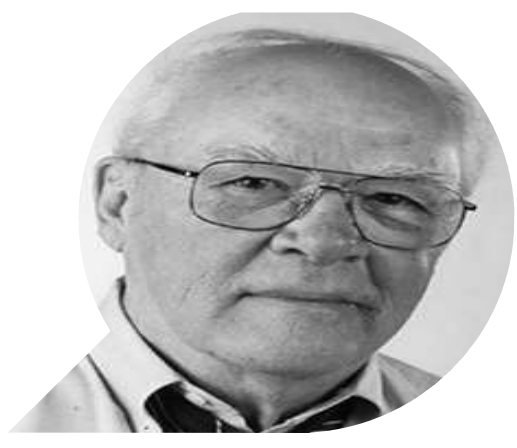

\section{O Civic Journalism / Public Journalism examinado por um de seus criadores}

\section{MARCIO FERNANDES ${ }^{1}$}

Davis Merritt é uma lenda no Jornalismo internacional. Lenda no melhor sentido que a palavra pode ter. Autor de quatro livros (o mais recente em 2015, chamado On life, liberty and the pursuit of perfect), esteve no topo do Jornalismo americano por mais de quatro décadas, atuando especialmente para a cadeia Knight Newspapers. Atuou como professor na University of Kansas e na Wichita State University. E, entre 1975 e 1997, atuou na liderança do Wichita Eagle, um diário no qual faria história, ao lançar as bases do que hoje se conhece como Civic Journalism (CJ), uma proposta fundada na visão de que, mais do que simplesmente denunciar problemas da vida em sociedade, o jornalista deve pensar em soluções e, especialmente, estimular a participação do cidadão na vida coletiva.

$\mathrm{Na}$ entrevista a seguir, Merritt compartilha informações preciosas sobre esse movimento que surgiu no final da década de 1980, ganhou corpo nos anos 1990 e começou a definhar a partir de 2000. No auge, o Civic Journalism era notícia e produzia notícias nos EUA, Colômbia, Bolívia, Argentina, Brasil, Portugal, Espanha e em muitos outros países. Agora, mais de 30 anos depois de suas primeiras inquietações sobre os rumos de então do Jornalismo, Merritt rememora os tempos inaugurais (inclusive destacando o papel de Jay Rosen, considerado o outro criador do Civic Journalism), esclarece a questão Civic Journalism / Public Journalism

1 Marcio Fernandes é cientista de Mídias e líder em projetos educacionais envolvendo América Latina e Europa. Jornalista com 23 anos de carreira no Brasil e no exterior, é doutor em Comunicação e Cultura (UFRJ/Brasil e UL/Portugal) e autor de diversos papers sobre Civic Journalism, publicados em vários países. Professor efetivo do Departamento de Comunicação Social (Decs) da Universidade Estadual do Centro-Oeste (Unicentro/Paraná/Brasil). E-mail: marciofernandes@unicentro.br 
(que, aliás, ele prefere, como se percebe em todas as suas respostas) e pensa sobre o tempo presente.

Sobre este quesito Civic Journalism / Public Journalism, cabe destacar o que segue: todos as perguntas feitas a Merritt fazem menção ao Civic Journalism, já que esta é a denominação mais conhecida no Brasil e em outras nações. Merritt, como ponderado antes, prefere Public Journalism (PJ). Por uma questão de respeito à opinião do entrevistado, mantivemos $\mathrm{PJ}$ em suas respostas. Essa dualidade, inclusive, é parte da riqueza dessa conversa sobre uma das mais inovadoras formas de se pensar e fazer Jornalismo nos últimos 50 anos. Confira:

Palavras-Chave: Civic Journalism; Public Journalism; Democracia

DM: Antes de começar a responder suas perguntas, gostaria de esclarecer a confusão sobre o nome do que criamos. Eu chamo isso de Jornalismo Público pois esse é o nome que Jay Rosen (professor universitário americano) e eu estabelecemos enquanto estávamos pensando juntos sobre o conceito, começando em 1993. Como o conceito era novo, nós reconhecemos que ele precisava de um nome mas temia que, ao dar a ele um nome, colocaríamos a proposta em uma espécie de caixa. Nós não estávamos tentando construir uma "coisa" que pudesse caber em uma caixa. Estávamos tentando iniciar uma discussão dentro da profissão sobre como a relação entre Jornalismo eDemocracia poderia ser mais eficaz para ambos.

Eventualmente, nós escolhemos "público" por duas razões principais: 1) Estávamos falando sobre a dinâmica da vida pública - como a Democracia é expressa e vivenciada; 2) Nós seríamos abertos a debater nossas intenções. Depois que Jay e eu publicamos uma primeira proposta das ideias (em "Teoria e Prática do Jornalismo Público") em 1994, isso começou a gerar alguma discussão dentro da profissão. Ed Fouhy, um ex-produtor de notícias da rede Knight Newspapers, visitou Wichita por dois dias para falar sobre a ideia. Mais tarde naquele ano, com dinheiro fornecido pelo Pew Charitable Trust, Fouhy usou nossas propostas para abrir o Pew Center for Civic Journalism. Mas nunca ficou clara a razão pela qual ele sentiu a necessidade de mudar o nome. Como o Center era apoiado por milhões de dólares do Pew, isso foi capaz de gerar a atenção que um editor de jornal e um professor de Jornalismo não pud- 
eram. Então, as pessoas começaram a usar o termo "Jornalismo Cívico".

Em 1995, publiquei o primeiro livro sobre o assunto (Jornalismo Público e Vida Pública: Por que contar notícias não é suficiente). Infelizmente, a confusão sobre o nome tornou muito mais difícil convencer os jornalistas norte-americanos ligados à tradição a entender e adotar as práticas que estávamos explorando. Ms, para ser justo, o Pew Center for Civic Journalism, sem dúvida, fez muito para espalhar algumas das ideias dentro da profissão, usando milhões de dólares para ajudar a financiar projetos em todo o território americano.

MF: Cerca de 30 anos atrás, o senhor apresentou a ideia do Civic Journalism (CJ), a partir da sua experiência como editor-chefe do jornal Wichita Eagle. Já é possível fazer um balanço sobre o que podemos chamar de 'legado do Civic Journalism'?

DM: É extremamente difícil pesar e medir o "legado" do Public Journalism do ponto de vista agora, em 2019. Sem dúvida, teve algum impacto sobre como o Jornalismo era praticado nos anos 90 e início dos anos 2000. Para estimular o assunto, mais de 50 livros e centenas de artigos acadêmicos sobre o assunto em várias línguas acabaram publicados. Mas como o Public Journalism é tanto um estado mental quanto uma maneira particular de fazer Jornalismo. Assim, é impossível avaliar seu impacto nos jornalistas de hoje. Ocasionalmente, vejo exemplos que considero estar no espírito e no modo do Public Journalism, mas é impossível estabelecer uma conexão concreta com nossas ideias depois de algumas décadas.

MF: O CJ surgiu como um furacão. Primeiramente, nos Estados Unidos. Em poucos anos, experiências muito interessantes estavam em curso na Colômbia, Argentina, Bolívia, Brasil, Espanha e outros lugares. O que causou o esfriamento dessa corrente do Jornalismo contemporâneo? Há uma grande razão ou diversos fatores ao longo dos anos seguintes ao ímpeto inicial?

DM: Certamente não há uma única razão à qual eu atribuísse o "resfriamento". Só posso atestar o que observei nos Estados Unidos e uma razão geral foi que poucos jornalistas norte-americanos levaram a sério 
a necessidade de reformas, particularmente os que trabalhavam nos grandes veículos. Os jornalistas dos principais jornais e redes geralmente não estão abertos à sugestão de que não estão fazendo tudo certo; afinal, eles estão no topo e não consideram que poderiam aprender alguma coisa com o editor de um jornal do Meio-Oeste americano, de tamanho médio, e com um professor de Jornalismo muito jovem.

Outras razões, não necessariamente nessa ordem:

1. O Public Journalism surgiu nos anos 90, assim como a influência negativa de Wall Street sobre os jornais de capital aberto, que estavam recursos em nome de lucros cada vez maiores. Fazer o Public Journalism não é barato e requer alguns riscos. Os anos 90 foram uma época em que as demandas de lucros de Wall Street já estavam reduzindo o conteúdo dos jornais. Em certo sentido, gostaria que tivéssemos pensado em Public Journalism no final dos anos 1970 ou 1980. A necessidade de reforma era clara para alguns de nós até então, mas os jornais estavam obtendo lucros consideráveis e não conseguiam ver nenhum fim para eles. Logo, qual a razão para mudar naquele momento?

2. O Public Journalism era sim Jornalismo. Fiquei chocado e desapontado com meus primeiros encontros para falar sobre isso, quando o tema se tornou alvo de cobertura jornalística. Jay e eu fomos entrevistados por repórteres que não leram nosso material, incluindo o primeiro manifesto e meu livro "Jornalismo Público e Vida Pública".

Um dia, juntos, passamos mais de cinco horas com um repórter de uma importante revista, explicando pacientemente o que estávamos fazendo. A história dela - que foi a primeira grande a aparecer em nível nacional - foi enquadrada de uma forma que nos fez parecer evangelistas itinerantes pregando algum tipo de nova religião do Jornalismo.

Repetidas vezes, os repórteres telefonavam e diziam: "Diga-me em um parágrafo sobre o que é o Public Journalism”, o que simplesmente não era possível, especialmente para alguém que não fez nenhuma lição de casa antes de ligar. Nunca fui entrevistado por um jornalista dos EUA que havia se preparado adequadamente para a tarefa. Foi 
tudo "agarrar e ir". Em contraste, os vários jornalistas estrangeiros que me entrevistaram - incluindo da Suécia, Chile, Argentina, Costa Rica, Japão, Nova Zelândia, Austrália - fizeram sua lição de casa. Certa vez, o editor emérito do The New York Times (diário americano) telefonou dizendo que queria escrever um artigo aberto sobre o Public Journalism. De suas primeiras perguntas, ficou claro que ele não havia lido nada além daquela reportagem de revista que mencionei antes. Eu disse: "Se você quer saber minhas opiniões sobre isso, acabei de terminar um livro sobre isso. Foi publicado do outro lado do rio, em Nova Jersey, e eu posso deixar em sua mesa pela manhã". Ele disse: "Não, obrigado", e começou a escrever um artigo condenando nossas ideias.

3. Em parte por causa da abordagem do Pew, o Public Journalism tornou-se identificado como um método mais do que como uma filosofia; como uma sacola de truques jornalísticos, em vez de uma atitude e crença sobre o papel do Jornalismo no processo de Democracia. Como a motivação do lucro de Wall Street sugou os recursos das redações, as possibilidades de demonstrar a utilidade de uma mudança de atitude diminuíram.

Além disso, por causa do modo Pew para financiar grandes projetos e pelo fato de que a cobertura inicial do Public Journalism focou em alguns dos principais projetos que fizemos no The Wichita Eagle, todo o movimento foi identificado como orientado a projetos quando, de fato, o aspecto mais interessante do movimento era o esforço para mudar a maneira como os jornalistas percebiam seu papel e a responsabilidade em uma Democracia. Embora os projetos importantes sejam caros, uma mudança é uma perspectiva que não custa nada, exceto o esforço para entender por qual motivo a mudança é necessária. Essa parte do Public Journalism rapidamente se perdeu.

Francamente, muitos jornalistas não estavam - e ainda não estão - interessados no desafio intelectual e filosófico que o movimento apresentava. Alguns apenas ignoraram. Outros diziam: "Apenas me diga como fazer isso; não me incomode com as razões". Outros ainda não entendiam - ou não queriam entender - que a maneira como faziam seu trabalho tinha muito a ver com o funcionamento da vida pública. Eles se recusaram a aceitar a responsab- 
ilidade pela maneira como coletaram e apresentaram as informações.

MF: Vários pensadores se tornaram experts sobre CJ nos primeiros anos. Jay Rosen e Jan Schaffer nos Estados Unidos, por exemplo. Ana Maria Castellanos na Colômbia. Carlos Castilho e Luiz Martins no Brasil. Francisco Seoane na Espanha. Em Portugal, Nelson Traquina. E Sabrina Carrasco na Argentina. O senhor tem acompanhado algum escritor nos últimos anos acerca do Civic Journalism?

DM: Já faz muito tempo desde eu que li alguma coisa sobre o Public Journalism em qualquer lugar. Se ainda tem sido uma questão de interesse além dos EUA nos últimos 10 anos, eu não estou ciente disso. No que diz respeito aos EUA, ele desapareceu por volta de 2003.

MF: Uma questão polêmica sempre foi a nomenclatura. Hoje, o senhor prefere falar em Public Journalism, em vez de Civic Journalism. O que é possível dizer sobre a relevância desta questão?

DM: A nomenclatura é muito relevante no que diz respeito à precisão histórica. Quando Jay e eu estávamos debatendo sobre que chamar, eu sugeri ironicamente "Banana", simplesmente como uma forma de evitar que o nome atrapalhasse os objetivos. Quando o Pew Center escolheu chamar de "Civic", isso realmente causou confusão e, a meu ver, prejudicou a causa que todos tentávamos alcançar.

MF: Outro item que sempre chamou muita atenção: o Civic Journalism parece ser se ajustado melhor ao Jornalismo Impresso, em especial pequenos e médios jornais diários. Com a decadência desse tipo de mídia, pode estar aí uma explicação para o CJ também não ter progredido tanto?

DM: Como mencionei acima, a Grande Mídia simplesmente não viu a necessidade de mudar, apesar de muitas pesquisas demonstrarem essa necessidade. As grandes redes jornalísticas americanas sempre estiveram muito preocupadas com suas posições nos rankings de audiência - e não o impacto de seu Jornalismo na vida pública e na Democracia. Além disso, as propostas do Public Journalism eram naturalmente at- 
raentes para veículos menores, pois as pessoas que dirigem e possuem esses jornais estão mais próximas de suas comunidades. Eles estão muito melhor posicionados para entender a importância de seus jornais enquanto uma parte útil das sociedades as quais servem. Mas, na verdade, o Public Journalism - particularmente a parte da atitude - é bem adequado a qualquer forma de Jornalismo, incluindo os meios digitais.

MF: Autores como a brasileira Silvia Moretzshon destacam que o Jornalismo 'se justifica historicamente pelo ideal iluminista de esclarecer os cidadãos'. O Civic não lhe parece esse ideal elevado a um patamar máximo?

DM: Certamente. Todas as civilizações que aspiram à liberdade individual e ao autogoverno requerem três componentes importantes: informações compartilhadas, um método ou lugar para discutir as implicações dessas informações e alguns outros valores compartilhados - pelo menos, uma crença na própria liberdade. O Jornalismo fornece informações compartilhadas e formas de discutir o que fazer com essas informações, e, portanto, apoia a ideia de liberdade. O objetivo do Public Journalism é fazer essas coisas sem consciência de si; isto é, intencionalmente, e não apenas como um artefato da atividade de reportar notícias. Dizer, como muitos jornalistas norte-americanos fazem, que "meu trabalho é apenas contar as notícias; o que as pessoas fazem com isso não me interessa ", é não apenas negar a realidade humana, mas também rejeitar qualquer responsabilidade pelas consequências de como eles fazem esse trabalho.

MF: Robert Merton e Paul Lazarsfeld, pensadores americanos, escreveram que boa parte da sociedade costumava ir dormir de consciência tranquila - por supostamente estarem bem informados mas sem ter feito efetivamente nada para a mudar a realidade social. O Civic Journalism é uma tentativa de acabar com essa 'disfunção narcotizante', como definiram os dois pensadores?

DM: Esse é um ótimo termo, “disfunção narcotizante”. O objetivo final do Public Journalism não era simplesmente reformar a prática do Jornalismo. Mas a reforma foi um passo necessário para alcançar o objetivo final de ajudar a vida pública a ir melhor - isto é, resolver problemas, alcançar 
a paz e a prosperidade -, mostrando às pessoas a possibilidade e o valor de seu engajamento nela. Muito da nossa vida pública - incluindo a vida política - e muito do Jornalismo é praticado de forma a desencorajar as pessoas a se envolverem. Muitas vezes, o modo como as histórias são concebidas e enquadradas define os cidadãos como espectadores ou vítimas, incapazes de uma ação significativa. O Public Journalism, entre muitas outras metas, procura enquadrar histórias de maneiras que demonstram como os cidadãos podem se engajar utilmente na vida pública.

MF: O CJ é uma espécie de antítese da Teoria do Espelho, ainda hoje uma importante Teoria do Jornalismo em muitas partes do mundo, especialmente do Ocidente. Ou é possível levar CJ e Teoria do Espelho lado a lado em projetos de CJ?

DM: Eu nunca fui um fã da Teoria do Espelho, com seu sentido tradicional e simplista, que é, como você sugere, a antítese do Public Journalism. Levantar um espelho para a sociedade refletirá apenas o que está lá e o que as pessoas dessa sociedade escolhem ver. A sociedade não vai se autocorrigir apenas na base de ser dito - ou mostrado - quão ruim é. Simplesmente refletir sobre a sociedade é outra maneira pela qual os jornalistas tradicionais se isentam da responsabilidade pela maneira como fazem seu trabalho.

MF: No começo dos anos 2000, justamente quando o CJ começa a perder força, surgem vertentes como Open Journalism e mesmo o Citizen Journalism muda de configuração - muitos autores celebraram os blogs e as possibilidades de que qualquer pessoa pudesse postar seus comentários na Internet como uma nova forma de Jornalismo. O Open Journalism chegou a ser visto como a salvação do Jornalismo, o que não aconteceu. Hoje, o que lhe parece esse cenário todo?

DM: O cenário é aterrorizante para a vida pública e apresenta um conjunto muito grande de questões a serem tratadas aqui. Como mencionado acima, a informação compartilhada é um componente necessário da autogovernança. Open Journalism é um equívoco, um abuso do termo. O Jornalismo é mais do que coletar e distribuir dados. O Jornalismo real tem um componente ordenador e um com- 
ponente de fornecimento de contexto. As organizações jornalísticas têm uma estrutura, uma hierarquia decisória. Simplesmente transmitir palavras e opiniões não se traduz como Jornalismo em nenhum sentido significativo. Eu acho provável que, com o tempo, algumas entidades on line verdadeiramente jornalísticas surjam como confiáveis. Mas, até então, o mundo estará em uma trajetória áspera e confusa. Espero que a Democracia sobreviva à essa fase adolescente.

MF: Na metade dos anos 2000, o professor Lewis Friedland (Wisconsin University/EUA) liderou uma impressionante investigação que mapeou mais de 600 projetos em seu país sobre o CJ. Agora, seria o momento de pensarmos em um novo diagnóstico, decorridos 30 anos, quem sabe até envolvendo outros países? Se sim, é possível antever algum prognóstico?

DM: Seria interessante se alguém pudesse replicar o alto nível de pesquisa que Lewis usou. Eu não posso prever o resultado de um projeto de pesquisa tão bem formulado. O Public Journalism sobreviveu às dores do parto e ainda existem vestígios em alguns lugares hoje? Afinal, alguns jornalistas passaram a entender seus papéis de forma diferente? Que diferenças esses projetos fizeram na vida pública das comunidades em que ocorreram? Muitas questões para se abordar mas um projeto muito difícil de realizar agora.

MF: De todos os projetos de CJ que o senhor ajudou a construir ou acompanhou noticiário, quais é possível destacar como especiais, seja pelo método empregado ou pelos resultados obtidos?

DM: As mudanças na cobertura das eleições que o Wichita Eagle desenvolveu no início dos anos 90 estariam no topo de uma lista de projetos eficazes, em parte pelo fato de que fizemos deliberadamente como um experimento e os resultados foram confirmados por pesquisas sérias. Durante um período eleitoral, dois momentos estão acontecendo: a campanha e a eleição. A campanha é o que os políticos e seus manipuladores fazem. A eleição - decidir em quem votar - é o que as pessoas fazem. A cobertura eleitoral tradicional sempre foi focada na campanha. Na época, decidimos concentrar nossa cobertura na eleição. 
Nós pesquisamos os eleitores para descobrir o que os preocupava em suas vidas. Em seguida, perguntamos aos candidatos por suas posições sobre as preocupações dos cidadãos. Isso se tornou parte importante de nossa cobertura, juntamente com a cobertura normal dos eventos de campanha. Após a eleição, nós estudamos o comparecimento dos eleitores e descobrimos que havia sido mais alto que o normal nas áreas geográficas onde nosso jornal circulava e mais baixo do que o normal em outros lugares. Também testamos como os eleitores entenderam os problemas coletivos em nossa área e fora de nossa área de atuação (do Wichita). Os eleitores com acesso à nossa cobertura entenderam as questões muito mais profundamente do que os eleitores que não viram nossa cobertura jornalística. No período eleitoral seguinte, outros jornais em outros estados americanos usaram nossa abordagem e obtiveram resultados semelhantes. Esta abordagem não foi muito bem vista pelos candidatos, pois essa técnica havia proporcionado mais controle sobre a eleição em favor dos cidadãos. Esse, claro, era o nosso objetivo.

MF: Em 2015, Jan Schaffer declarou que, de todos os projetos apoiados pelo Pew Center sobre Civic Journalism, 78\% apresentaram algum tipo de solução para os problemas que eram tratados nesses projetos e que mais de $50 \%$ das propostas patrocinadas tiveram soluções apresentadas pelos próprios cidadãos/leitores. São percentuais espetaculares, não?

DM: Esse era o objetivo do Public Journalism desde o início: fazer Jornalismo de forma a ajudar os cidadãos a resolverem os problemas da sociedade. Funcionou naqueles lugares onde os jornalistas entendiam os conceitos e os praticavam.

MF: Há um futuro para o Civic Journalism, especialmente neste momento em que vivemos com a onipresença das Fake News? Não é demais lembrar que, em 2005, Allan Wolper (na publicação Editor \& Publisher) decretou a morte do Civic J, quando da transformação do Pew Center for Civic Journalism em J-Lab: The Institute for Interactive Journalism...

DM: Eu não vi a fala de Wolper. Em 2005, o Public Journal- 
ism não estava mais na agenda da maioria dos jornais pois não havia mais tempo nem dinheiro para experimentos sérios.

MF: E há um futuro para a Mídia Impressa diária? Ou, melhor, há um bom futuro para a informação devidamente checada na Mídia Impressa ou o Jornalismo está destinado a ser absorvido lentamente pelos conteúdos que são feitos apenas para divertir?

DM: Como escrevi no livro "Knightfall", em 2006, a questão em sociedades democráticas não é se os jornais sobrevivem - isso não ocorrerá pois seu modelo financeiro está destruído. A questão é saber se o tipo de Jornalismo que veículos tradicionais sempre fizeram pode ser migrado para plataformas digitais. Até agora, há pouca evidência de que isso está ocorrendo. Como mencionei acima, as organizações jornalísticas que compreendem e executam as tarefas contextuais tradicionais enquanto coletam e publicam informações podem funcionar com tanto sucesso no mundo digital quanto no mundo dos impressos. Mas a questão é se pessoas em volume suficiente estão dispostas a pagar dinheiro para apoiar esse esforço on line, em um ambiente no qual a maioria das pessoas espera que tudo seja gratuito. Não sabemos como pode ser um modelo de negócios de sucesso para o Jornalismo on line e não temos muito tempo para descobrir. Essa é a parte desanimadora.

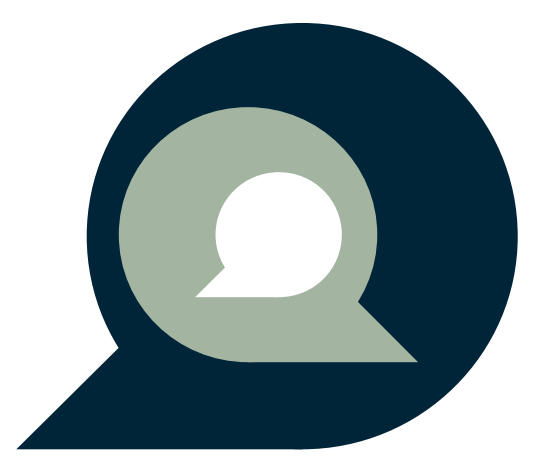

